Research

\title{
Effects of whole body exposure to extremely low frequency electromagnetic fields (ELF-EMF) on serum and liver lipid levels, in the rat
}

\author{
Patricia V Torres-Duran1, Aldo Ferreira-Hermosillo², Marco A Juarez- \\ Oropeza$^{1}$, David Elias-Viñas ${ }^{3}$ and Leticia Verdugo-Diaz ${ }^{* 4}$
}

\begin{abstract}
Address: ${ }^{1}$ Department of Biochemistry, School of Medicine, UNAM. P.O. Box 70159, Mexico, D.F. 04510, Mexico, ${ }^{2}$ Department of Biochemistry, School of Medicine, UNAM. Scholarship holder PAPITT IN218107 and AFINES, Mexico, ${ }^{3}$ Department of Electrical Engineering, Section of Bioelectronics, CINVESTAV, IPN, Mexico, D. F., 07360, Mexico and ${ }^{4}$ Department of Physiology, School of Medicine, UNAM. P.O. Box 70250, Mexico, D. F. 04510, Mexico

Email: Patricia V Torres-Duran - pavito@correo.unam.mx; Aldo Ferreira-Hermosillo - aldo_fh@tutopia.com; Marco A JuarezOropeza - majo_ya@yahoo.com; David Elias-Viñas - delias@cinvestav.mx; Leticia Verdugo-Diaz* - leticia@servidor.unam.mx

* Corresponding author
\end{abstract}

Published: 16 November 2007

Lipids in Health and Disease 2007, 6:31 doi:I0.1I86/I476-5IIX-6-31

This article is available from: http://www.lipidworld.com/content/6/I/31

(c) 2007 Torres-Duran et al; licensee BioMed Central Ltd.

This is an Open Access article distributed under the terms of the Creative Commons Attribution License (http://creativecommons.org/licenses/by/2.0), which permits unrestricted use, distribution, and reproduction in any medium, provided the original work is properly cited.
Received: 17 August 2007

Accepted: 16 November 2007

\begin{abstract}
Backgound: The effects of extremely low-frequency electromagnetic fields (ELF-EMF) on the blood serum and liver lipid concentrations of male Wistar rats were assessed.

Methods: Animals were exposed to a single stimulation ( 2 h) of ELF-EMF $(60 \mathrm{~Hz}, 2.4 \mathrm{mT})$ or shamstimulated and thereafter sacrificed at different times (24, 48 or $96 \mathrm{~h}$ after beginning the exposure).

Results: Blood lipids showed, at $48 \mathrm{~h}$ stimulated animals, a significant increase of cholesterol associated to high density lipoproteins (HDL-C) than those observed at any other studied time. Free fatty acid serum presented at $24 \mathrm{~h}$ significant increases in comparison with control group. The other serum lipids, triacylglycerols and total cholesterol did not show differences between groups, at any time evaluated. No statistical differences were shown on total lipids of the liver but total cholesterol was elevated at $24 \mathrm{~h}$ with a significant decrease at $96 \mathrm{~h}(\mathrm{p}=0.026)$. The ELF-EMF stimulation increased the liver content of lipoperoxides at $24 \mathrm{~h}$.
\end{abstract}

Conclusion: Single exposures to ELF-EMF increases the serum values of HDL-C, the liver content of lipoperoxides and decreases total cholesterol of the liver. The mechanisms for the effects of ELFEMF on lipid metabolism are not well understand yet, but could be associated to the nitric oxide synthase EMF-stimulation.

\section{Background}

Some recent epidemiologic studies have suggested that the exposure to extremely low frequency (ELF) electromagnetic fields (EMF) affect human health, because of the incidence of certain types of cancer, depression, and miscarriage have been increased among individuals living or working in environments exposed to such fields [1-3]. Some of these studies have shown associations between exposure to power-frequency $(50-60 \mathrm{~Hz})$ magnetic fields and increased health risk $[4,5]$, but other studies have not shown such a link [6]. The results described above are not 
completely conclusive, since in several cases they are contradictory.

Extremely low-frequency electromagnetic fields exposure is generally believed to be innocuous for human health due to their low-level energy exposition, which is of a magnitude well below that required to affect the metabolic rate of the human body $[3,7,8]$. However, an increasing number of studies have reported that ELF-EMF exposure is capable to eliciting in vivo and in vitro bioeffects [9-12]. ELF-EMF exposure has shown to increase oxidative-stress in some models like chick embryos [13], mammalian cultured cells [14], and human erythrocytes [15]. The increased oxidative-stress involves oxidative DNA damage, lipid peroxidation [16], and may cause a number of systemic disturbances [17].

Spreading evidence suggests that environmental and artificial magnetic fields have significant impact on cardiovascular systems of animals and humans [18-21]. Recent studies showed that static magnetic fields decreased arterial baroreflex sensitivity in rabbits [22]. Under pharmacologically induced hypertensive conditions, the exposure to nonuniform MF to rabbits, significantly attenuated the vasoconstriction and suppressed the elevation of blood pressure [23]. In contrast, microwaves increase skin temperature and therefore cause vasodilatation in normal subjects exposed during 30 minutes [24]. Also, human blood platelets exposed in vitro to microwaves produced by mobile phones (operating at $900 \mathrm{MHz}$ ), increased the thiobarbituric acid reactive substances (TBARS) production and significantly depleted the superoxide dismutase1 activity [17]. Recently, it has been studied the possibility that heat generation and the activation of the inducible form of nitric oxide (NO) synthase may be the possible causes of the biological effects of EMF exposure [25-27].

On the other hand, beneficial effects of ELF-EMF have also been reported. In diet-induced hypercholesterolemic rabbits, pulsed of EMF lowers total cholesterol and triacylglycerols levels [28]; similar results have been found in rats [29] and mice [30], both fed on control diets. Despite the above mentioned studies, there are not enough data to know the time-course effects of ELF-EMF on lipid and lipoperoxide levels in biological models. Then, the aim of the present study was to investigate, in the rat, the timecourse effects of a single ELF-EMF stimulation on serum and liver lipid concentrations, as well as liver lipoperoxide production.

\section{Results}

Serum lipid concentrations

There were no significant differences between experimental and control groups for triacylglycerols and total cholesterol serum levels, at any time analyzed. However, $48 \mathrm{~h}$ after beginning the treatment, HDL-C concentrations were higher in stimulated rats $(48.2 \pm 4.3 \mathrm{mg} / \mathrm{dL})$ than those observed in control group $(38.7 \pm 7.1 \mathrm{mg} / \mathrm{dL})$; however, a significant decrease on HDL-C levels was observed at $96 \mathrm{~h}$ in ELF-EMF stimulated rats $(24 \mathrm{~h} 46.1 \pm 8.1 \mathrm{mg} / \mathrm{dL}$ and $96 \mathrm{~h} 29.24 \pm 2.20 \mathrm{mg} / \mathrm{dL}$ ) (Fig. 1). On the other hand, FFA serum levels increased at $24 \mathrm{~h}(20 \pm 2.25 \mathrm{mg} / \mathrm{dL})$ with a statistically significant difference respect control (16.6 \pm $3 \mathrm{mg} / \mathrm{dL} ; \mathrm{p}=0.026)$ but no differences were found at 48 or $96 \mathrm{~h}$ (Fig. 2).

\section{Liver analyses}

There were no significant differences, in total lipids, triacylglycerols and protein values at any time $(24,48$ and 96 $\mathrm{h}$, data not shown). Liver total cholesterol showed a transient increase level at $24 \mathrm{~h}(48.6 \pm 8.3 \mathrm{mg} / \mathrm{dL})$ that decreased at $96 \mathrm{~h}(32.8 \pm 6.1 \mathrm{mg} / \mathrm{dL} ; \mathrm{p}=0.026)$ (Fig. 3). Furthermore, liver TBARS concentration was the variable where the ELF-EMF exposure induced major increases 24 $\mathrm{h}$ after beginning the treatment $(198.80 \pm 56.9$ vs. control group $102.18 \pm 27.8 \mathrm{ng} / \mathrm{mg}$ total lipids) meanwhile no significant differences were found at 48 or 96 h (Fig. 4).

\section{Discussion}

Extremely low frequency electromagnetic fields interact with an animal by inducing electric fields inside the body. These induced fields represent the internal exposure or "dose" [31]. In living animals, a variety of natural endogenous electric fields also exist internally. These fields arise from normal physiological activity, and extend into adjacent tissues throughout the body. The endogenous fields

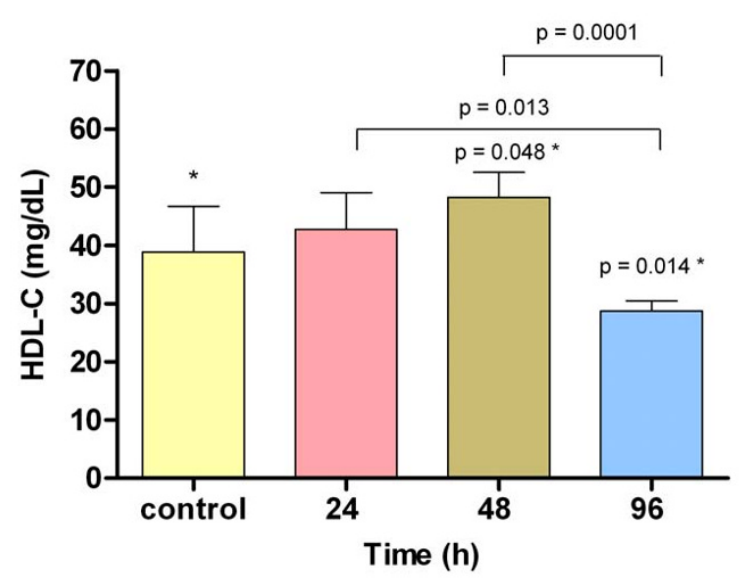

Figure I

High density lipoprotein cholesterol serum levels in control group and 24, 48 and $96 \mathrm{~h}$ after ELF-EMF exposure. * Values significantly different in comparison with control group by ANOVA. A significant decrease was observed at $96 \mathrm{~h}$ in comparison with 24 and $48 \mathrm{~h}$ by ANOVA. 


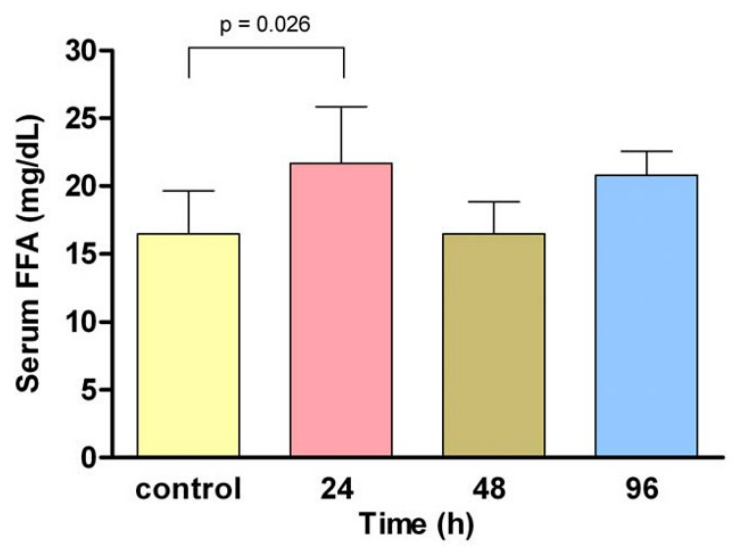

Figure 2

Free fatty acid serum levels in control group and 24, 48 and $96 \mathrm{~h}$ after ELF-EMF exposure. A significant increase was observed at $24 \mathrm{~h}$ in comparison with control group by ANOVA.

will combine by simple addition with any field induced by external exposure to electromagnetic fields.

Some studies about biological effects due to $50-60 \mathrm{~Hz}$ electromagnetic fields exposure have been performed with rodents and other animal models [32,33]. Assessment of possible human health effects has been to a certain extent supports on these studies. It has been recognized that induced electric field in rodents are much lower than in humans for the same exposure field [34], this is a direct result of differences in size [35].

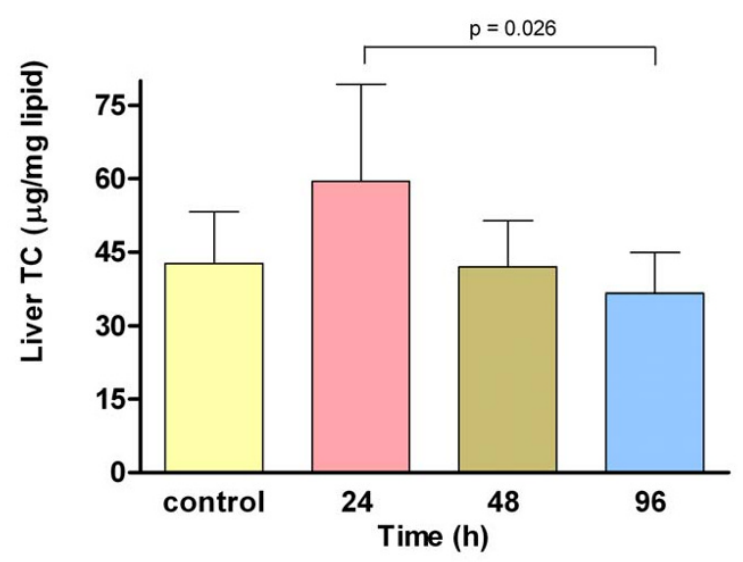

Figure 3

Total cholesterol liver levels in control group and at 24, 48 and $96 \mathrm{~h}$ after ELF-EMF exposure. A significant decrease was observed at $96 \mathrm{~h}$ in comparison with $24 \mathrm{~h}$ by ANOVA.

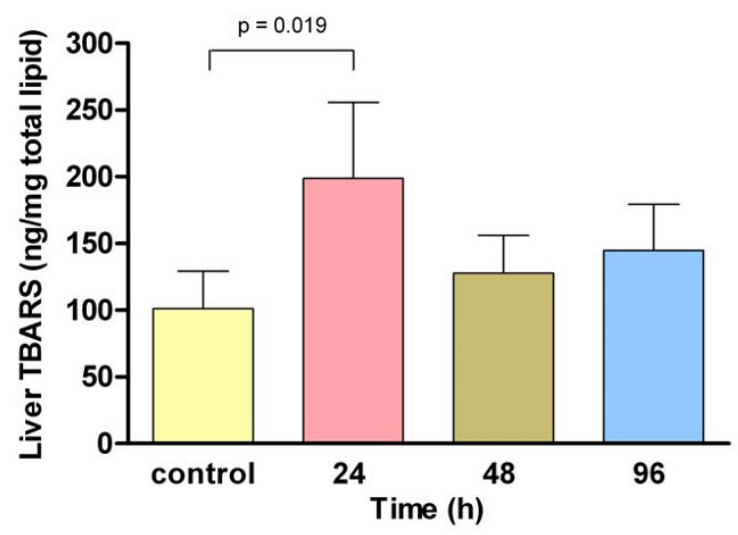

Figure 4

Thiobarbituric acid reactive substances liver levels in control group and 24, 48 and $96 \mathrm{~h}$ after ELF-EMF exposure. A significant increase was observed at $24 \mathrm{~h}$ in comparison with control group by ANOVA.

Since in situ measurement of induced field cannot be performed in humans, dosimetric models and animal studies are used. Comparisons of all dosimetric models are agreed within $2 \%$ or less; however, differences dues of size, shape, postural and individual organ have been observed [36].

In the present study, we use the rodent model to test the time-course effects of a single exposure to ELF-EMF (60 $\mathrm{Hz}, 2.4 \mathrm{mT}$, by two hours) on serum and liver lipids, as well as liver lipoperoxide content. The whole body exposure approach could stimulate any tissue; however, among the most susceptible tissues to EMF exposure are brain, blood and liver [37]. No changes were observed in total cholesterol and triacylglycerol serum levels. But HDL-C and free fatty acids, were higher at 48 and 24 hours, respectively, in stimulated group than in shamstimulated; however, only HDL-C showed lower levels at 96 hours after beginning the exposure. Our results are partially in accordance with previous studies showing that a single one hour exposure to a $12 \mathrm{~Hz}, 1.5-12 \mathrm{mT}$ pulsed magnetic fields decreased, in a reversible way, cholesterol and triacylglycerol plasma levels in male rats 24 hours after their exposure [29,38]. Furthermore, when hyperlipidemic diet-induced female rabbits were exposed to a 15 $\mathrm{Hz}, 0.4 \mathrm{mT}, 10$ hours/day by 8 weeks, both cholesterol and triacylglycerols were significantly decreased, while HDL-C values were increased [28]. Harakawa and colleagues [37] observed that the exposition for 14 days to ELF-electric fields of ischemic rats significantly decreased free fatty acids and triacyglycerol plasma levels. The fact that total cholesterol and triacylglycerol serum levels did not change in our study could be explained in part by the 
frequency and length of stimulation used, as well as the basal lipemia of animals. Because of changes in serum free fatty acid concentration under our experimental conditions were observed at $24 \mathrm{~h}$, it can be proposed that ELFEMF have early effects on adipocytes lipolysis, at least after a single EMF stimulation.

On the other hand, TBARS levels were also increased in experimental group at 24 hours after the exposure. Because of the nitric oxide (NO) synthase may be stimulated by the EMF exposure [25-27], and this compound has been involved in the stimulation of lipid peroxidation during the initial states of ischemia-reperfusion injury [39], it is possible that increased free fatty acid deposition in the liver after ELF-EMF could occur as a consequence of the NO production. This hypothesis could explain also the increased TBARS production in stimulated group.

Lipid peroxidation products have been accepted as biomarkers for oxidative stress in biological systems [40]. Furthermore, few studies have been focused on the involvement of oxidative stress in the action mechanism of EMF exposure $[41,42]$. Some authors have showed that exposition to electric fields $(50 \mathrm{~Hz})$ of Sprague-Dawley rats did not change the antioxidant activity and lipid peroxide level of unstressed animals but decreased the plasma peroxide level in stressed rats [43]. The authors suggest that the electric fields might have some influence on lipid peroxide metabolism. In the present study we also obtained changes in liver peroxide level when Wistar rats were exposed to electromagnetic fields. Recently, Zwirska-Korczala and colleagues [44] using preadipocytes, showed a diminution in the activity of superoxide dismutase after 24 and 48 h of EMF exposition (180$195 \mathrm{~Hz}$ ). The early increase in the liver TBARS concentration observed in our study after $24 \mathrm{~h}$ of EMF stimulation could be the result of the reduction in the activity of antioxidant enzymes or/and the increase of free radical production.

No differences were observed in cholesterol content of the liver between both groups studied. This result contrast with those finding in other studies [28,29], but could be explained by the different stimulation conditions used in that studies.

On the other hand, reduction in serum total lipids has also been observed in human beings. The most pronounced changes were found in steelworkers with the longest exposure (over 10 years) to electromagnetic fields [45].

\section{Conclusion}

In conclusion, the results described here demonstrate the adaptative temporary response on lipid metabolism after the single exposure to ELF-EMF. The increased TBARS level after a single exposure to ELF-EMF deserves more research in other ELF-EMF conditions. Although the mechanisms for the effects of ELF-EMF are not well understand yet, the effects described above could be useful in the comprehension of lipid changes observed during chronic exposure to ELF-EMF.

\section{Methods \\ Reagents}

All reagents and chemicals used were of analytical grade (Sigma-Aldrich, México). Solvents were purchased from Merck (México). Total cholesterol (TC), high-density lipoprotein cholesterol (HDL-C), triacylglycerols (TAG), and free fatty acids (FFA) were assessed by enzymatic kits (Roche, México).

\section{Animals}

Forty male rats of the Wistar strain, weighing 220-250 g were used. All animals were housed per group (five animals per acrylic cage) with free access to food and water, in a room with controlled temperature $\left(25 \pm 2{ }^{\circ} \mathrm{C}\right)$ and light-dark cycles (07:00 - 19:00 h, light on). All experiments were conducted during the light phase of the cycle, between 09:00 and 15:00 h.

All procedures were performed in strict accordance with the international guidelines for care of experimental animals.

The rats were either exposed to a single stimulation of ELF-EMF (experimental groups) or sham-stimulated (control groups). The time-course effects of the single ELF-EMF exposure on serum and liver lipid concentrations, as well as liver lipoperoxides (measured as TBARS) were assessed at 24, 48 and $96 \mathrm{~h}$ after beginning the treatment (five rats per group at each time).

\section{ELF-EMF exposure}

Electromagnetic field exposure was applied with a device used previously in our laboratory [46]. Electromagnetic fields were generated inside the exposure chamber with a pair of circular Helmholtz coils (30 cm internal diameter) composed of 18-gauge copper wire (350 turns). The two coils were connected in parallel to minimize the total impedance of the wire and to map the magnetic field. Coils were connected to a $120 \mathrm{~V}$ adjustable transformer (Staco Energy Products, Dayton, OH, USA). An oscilloscope (Tektronix, 5103N, USA) was coupled to the system for monitoring the $60 \mathrm{~Hz}$ sinusoidal MF waveform. Magnetic flux density was measured using a hand-held Gauss/ Tesla Meter (Alpha-Lab). The sinusoidal magnetic flux density was $2.4 \mathrm{mT}$. Helmholtz coils provide a very uniform field over a relatively large volume in the space between the coils. 
Coils were spaced apart at a distance equal to their radii in the upper and lower face of the plastic exposure chamber $(30 \times 30 \times 15 \mathrm{~cm})$. A single stimulation was applied during $2 \mathrm{~h}$ from 09:00 to 11:00 h. The exposure chamber housed five rats each experimental session. Sham-stimulated animals were maintained simultaneously to experimental animals for an equal period of time inside of another chamber with the coils turned off. The magnetic field ambient background level was $<0.04 \mathrm{mT}$. Inside the exposure chamber the temperature was $25.4 \pm 0.4{ }^{\circ} \mathrm{C}$ and illumination intensity was $17 \pm 2$ Lux.

\section{Serum analyses}

The animals were fasted twelve hours previously to the end of experimental period. The rats were anesthetized with diethyl ether and killed by cervical dislocation. The serum was obtained by blood centrifugation and stored at $-78^{\circ} \mathrm{C}$ until triacylglycerols, total cholesterol and free fatty acids were assessed. HDL-C was determined using aliquots of fresh serum.

\section{Liver analyses}

The liver was excised, weighed and stored at $-78^{\circ} \mathrm{C}$. For each liver, a sample of fresh tissue was obtained for lipid analyses.

Total lipids were extracted with chloroform-methanol $(3: 1 \mathrm{v} / \mathrm{v})$ by a modified Folch's method [47]. For liver samples, $1.0 \mathrm{~g}$ of fresh tissue was homogenized in 4 volumes of $0.05 \mathrm{M}$ phosphate buffer, $\mathrm{pH} 7.2$ containing $0.025 \%$ butylated hydroxytoluene (BHT), as antioxidant. Then, the $\mathrm{pH}$ was adjusted to 6.0 by the addition of $\mathrm{HCl}$ solution and this suspension was extracted three times with 3 volumes each of the chloroform-methanol mixture. The extract was washed with $10 \mathrm{~mL}$ of water, the organic fraction was evaporated under a nitrogen stream, then weighed (for total lipids), and stored at $-78^{\circ} \mathrm{C}$ until cholesterol, triacylglycerol, and TBARS analyses were performed. Liver lipoperoxides were measured by determining TBARS as previously described [48]. Total protein content was determinated in homogenate aliquots, using Bradford's method [49].

\section{Statistical analyses}

Results were evaluated by one way analysis of variance (ANOVA) except those from serum and liver triacylglycerols (Kolmogorov-Smirnov). Differences among groups were assessed by Tukey and Mann Withney-U tests, using SPSS software v. 12. A statistical $p$ value less than 0.05 was considered significant.

\section{Competing interests}

The author(s) declare that they have no competing interests.

\section{Authors' contributions}

PVTD participated in the collection, design, analysis and interpretation of data and writing of the manuscript; $\mathrm{AFH}$ participated in the collection and analysis of data and performed the statistical analysis; MAJO participated in the design, analysis and interpretation of data and writing of the manuscript; DEV participated in the design of equipment; LVD participated in the analysis and interpretation of data and writing of the manuscript. All authors read and approved the final manuscript.

\section{Acknowledgements}

This work was supported in part by a grant from PAPIIT-UNAM (IN2 I8107, MAJO).

\section{References}

I. Lacy-Hubert A, Metcalfe JC, Hesketh R: Biological responses to electromagnetic fields. FASEB J I 998, I 2:395-420.

2. Ahlbom A, Feychting M: Electromagnetic radiation. British Medical Bull 2003, 68:157-165.

3. Feychting M, Ahlbom A, Kheifets L: EMF and health. Annu Rev Public Health 2005, 26:165-189.

4. Valberg PA, Kavet R, Rafferty CN: Can low-level 50/60 Hz electric and magnetic fields cause biological effects? Radiation Research 1997, | 48:2-2I.

5. Wertheimer N, Savitz DA, Leeper E: Childhood cancer in relation to indicators of magnetic fields from ground current sources. Bioelectromagnetics 1995, I6(2):86-96.

6. Preece AW, Hand JW, Clarke RN, Stewart A: Power frequency electromagnetic fields and health. Where's the evidence? Phys Med Biol 2000, 45:139-154.

7. Adey WR: Tissue interactions with nonionizing electromagnetic fields. Physiol Rev I98I, 6 I(2):435-5I4.

8. Habash RW, Brodsky LM, Leiss W, Krewski D, Repacholi M: Health risks of electromagnetic fields. Part I: Evaluation and assessment of electric and magnetic fields. Crit Rev Biomed Eng 2003, 3 I(3): | $4 \mid-195$.

9. Litovitz TA, Montrose C], Wang W: Dose-response implications of the transient nature of electromagnetic-field-induced bioeffects: theoretical hypotheses and predictions. Bioelectromagnetics 1992:237-246.

10. Repacholi $\mathrm{MH}$, Greenebaum B: Interaction of static and extremely low frequency electric and magnetic fields with living systems: health effects and research needs. Bioelectromagnetics 1999, 20:133-160.

II. Foster KR: Mechanisms of interaction of extremely low frequency electric fields and biological systems. Radiat Prot Dosimetry 2003, 106(4):301-310.

12. Juutilainen J: Developmental effects of extremely low frequency electric and magnetic fields. Radiat Prot Dosimetry 2003, I 06(4):385-390.

13. Di Carlo AL, White NC, Litovitz TA: Mechanical and electromagnetic induction of protection against oxidative stress. Bioelectrochemistry 2000, 53:87-95.

14. Hook GJ, Spitz DR, Sim JE, Higashikubo R, Baty JD, Moros EG, Roti $\mathrm{JL}$ : Evaluation of parameters of oxidative stress after in vitro exposure to FMCW and CDMA modulated radio frequency radiation fields. Radiat Res 2004, I 62(5):497-504.

15. Dachà M, Accorsi A, Pierotti C, Vetrano F, Mantovani R, Guidi G, Conti R, Nicolini P: Studies on the possible biological effects of $50 \mathrm{~Hz}$ electric and/or magnetic fields: evaluation of some glycolitic enzymes, glycolitic flux, energy and oxido-reductive potentials in human erythrocytes exposed in vitro to power frequency fields. Bioelectromagnetics 1993, I4(4):383-391.

16. Yokus B, Cakir DU, Akdag MZ, Sert C, Mete N: Oxidative DNA damage in rats exposed to extremely low frequency electromagnetic fields. Free Radic Res 2005, 39(3):3 I 7-323.

17. Stopezyk D, Gnitecki W, Buczynski A, Markuszewski A, Buczynski J: Effect of electromagnetic field produced by mobile phones on the activity of superoxide (SOD-I) and the level of malo- 
nyldialdehyde (MDA) in vitro study. Med $\operatorname{Pr}$ 2002, 53(4):3||-3|4.

18. Sastre A, Graham C, Cook MR: Brain frequency magnetic fields alter cardiac autonomic control mechanisms. Clin Neurophysiol 2000, III (II):1942-1948.

19. Szmigielski S, Bortkiewicz A, Gadzicka E, Zmyslony M, Kubacki R: Alteration of diurnal rhythms of blood pressure and heart rate to workers exposed to radiofrequency electromagnetic fields. Blood Press Monit 1998, 3(6):323-330.

20. Graham C, Sastre A, Cook MR, Kavet R: Heart rate variability and physiological arousal in men exposed to $60 \mathrm{~Hz}$ magnetic fields. Bioelectromagnetics 2000, 2 I (6):480-482

2I. Jauchem JR, Frei MR, Ryan KL, Merritt JH, Murphy MR: Lack of effects on heart rate and blood pressure in ketamine-anesthetized rats briefly exposed to ultra-wideband electromagnetic pulses. IEEE Trans Biomed Eng 1999, 46(1): I 17- I 20.

22. Gmitrov J, Ohkubo C: Artificial static and geomagnetic field interrelated impact on cardiovascular regulation. Bioelectromagnetics 2002, 23(5):329-338.

23. Okano H, Ohkubo C: Anti-pressor effects of whole body exposure to static magnetic field on pharmacologically induced hypertension in conscious rabbits. Bioelectromagnetics 2003 24(2): |39-| 47.

24. Paredi P, Kharitonov SA, Hanazawa T, Barnes PJ: Local vasodilator response in mobile phones. Laryngoscope 200I, III(I):159-162.

25. Kavaliers M, Choleris E, Prato FS, Ossenkopp KP: Evidence for the involvement of nitric oxide and nitric oxide synthase in the modulation of opiod-induced antinociception and the inhibitory effects of exposure to $60-\mathrm{Hz}$ magnetic fields in the land snail. Brain Res 1998, 809(I):50-57.

26. Kim SS, Shin HJ, Eom DW, Huh JR, Woo Y, Kim H, Ryu SH, Suh PG, Kim MJ, Kim JY, Koo TW, Cho YH, Chung SM: Enhanced expression of neuronal nitic oxide synthase and phospholipase $C$ gammal in regenerating murine neuronal cells by pulse electromagnetic field. Esp Mol Med 2002, 34(I):53-59.

27. Seaman RL, Parker JE, Kiel JL, Mathur SP, Grubbs TR, Prol HK: Ultrawideband pulses increase nitric oxide production by RAW 264.7 macrophages incubated in nitrate. Bioelectromagnetics 2002, 23(I):83-87.

28. Luo EP, jiao LC, Shen GH, Wu XM, Cao YX: Effects of exposing rabbits to low-intensity pulsed electromagnetic fields on levels of blood lipid and properties of hemorheology. Chinese Clin Rehabilitation 2004, 8(18):3670-367I.

29. Bellossi A, Pouvreau-Quillien V, Rocher C, Ruelloux M: Effect of pulsed magnetic fields on triglyceride and cholesterol levels in plasma of rats. Panminerva Med 1998, 40(4):276-279.

30. Kumosani TA, Qari MH: The effect of magnetic field on the biochemical parameters of mice blood. Pak J Med Sci 2003 19(1):36-40.

31. Miller DL, Creim JA: Comparison of cardiac and $60 \mathrm{~Hz}$ magnetically induced electric fields measured in anesthetized rats. Bioelectromagnetics 1997, 18:317-323.

32. Babbit JT, Kharazi Al, Taylor JM, Boods CB, Mirell SG, Frumkin E, Zhuang D, Hahn TJ: Hematopoietic neoplasia in C57BL/6 mice exposed to split-dose ionizing radiation and circularly polarized $60 \mathrm{~Hz}$ magnetic fields. Carcinogenesis 2000, 2 I: I379-1389.

33. Morris JE, Sasser LB, Miller DL, Dagle GE, Rafferty CN, Ebi KL, Anderson LE: Clinical progression of transplanted large granular lymphocytic leukemia in Fischer 344 rats exposed to $60 \mathrm{~Hz}$ magnetic fields. Bioelectromagnetics 1999, 20:48-56.

34. NIEHS: Assessment of health effects from exposure to power-line frequency electric and magnetic fields. NIH Publication No. 981998.

35. Dawson TW, Caputa K, Stuchly MA: Electric fields induced in humans and rodents by $60 \mathrm{~Hz}$ magnetic fields. Phys Med Biol 2002, 47:256I-2568

36. Caputa K, Dimbylow PJ, Dawson TW, Stuchly MA: Modelling fields induced in humans by $50 / 60 \mathrm{~Hz}$ magnetic fields: reliability of the results and effects of model variations. Phys Med Biol 2002 47:1391-1398.

37. Harakawa S, Inoue N, Hori T, Tochio K, Kariya T, Kunihito Takahashi K, Doge F, Martin ED, Saito A, Suzuki H, Nagasawa H: Effects of exposure to a $50 \mathrm{~Hz}$ electric field on plasma levels of lactate, glucose, free fatty acids, triglycerides and creatine phosphokinase activity in hind-limb ischemic rats. J Vet Med Sci 2005, 67:969-974.
38. Bellossi A, Pouvreau-Quillien V, Rocher C, Ruelloux M: Effect of pulsed magnetic fields on cholesterol and triglyceride levels in rats study of field intensity and length of exposure. $Z$ Naturforsch 1996, 5 I (7-8):603-606.

39. Jaeschke $\mathrm{H}$ : Molecular mechanism of hepatic ischemia-reperfusion injury and preconditioning. Am J Physiol Gastrointest Liver Physiol 2003, 284:GI5-G26.

40. Laval J: Role of DNA repair enzymes in the cellular resistence to oxidative stress. Pathol Biol 1996, 44(I I): I4-24.

41. Moustafa YM, Moustafa RM, Belacy A, Abou-El-Ela SH, Ali FM: Effects of acute exposure to the radiofrequency fields of cellular phones on plasma lipid peroxide and antioxidase activities in human erythrocytes. J Pharm Biomed Anal 200I, 26(4):605-608.

42. Simko M, Droste S, Kriehuber R, Weiss DG: Stimulation of phagocytosis and free radical production in murine macrophages by $50 \mathrm{~Hz}$ electromagnetic fields. Eur J Cell Biol 200I, 80(8):562-566.

43. Harakawa S, Inoue N, Hori T, Tochio K, Kariya T, Takahashi K, Doge $F$, Suzuki $H$, Nagasawa $\mathrm{H}$ : Effects of a $50 \mathrm{~Hz}$ electric field on plasma lipid peroxide level and antioxidant activity in rats. Bioelectromagnetics 2005, 26:589-594.

44. Zwirska-Korczala K, Jochem J, Adamcczyk-Sowa M, Sowa P, Polaniak R, Birkner C, Latocha M, Pilc K, Suchanek R: Effect of extremely low frequency electromagnetic fields on cell proliferation, antioxidative enzyme activities and lipid peroxidation in 3T3-LI preadipocytes-an in vitro study. J Physiol Pharmacol 2005, 56(Supp 6): $101-108$

45. Kula B, Sobczak A, Grabowska-Bochenek R, Piskorska D: Effect of electromagnetic field on serum biochemical parameters in steelworkers. J Occup Health 1999, 4I:177-180.

46. Vázquez-García M, Elías-Viñas D, Reyes-Guerrero G, DomínguezGonzález A, Verdugo-Díaz L, Guevara-Guzmán R: Exposure to extremely low-frequency electromagnetic fields improves social recognition in male rats. Physiol Behav 2004, 82(4):685-690.

47. Torres-Durán PV, Miranda-Zamora R, Paredes-Carbajal MC, Mascher D, Ble-Castillo J, Díaz-Zagoya JC, Juárez-Oropeza MA: Studies on the preventive effect of Spirulina maxima on fatty liver development induced by carbon tetrachloride, in the rat. J Ethnopharmacol 1999, 64:141-147.

48. Torres-Durán PV, Paredes-Carbajal MC, Mascher D, ZamoraGonzález J, Díaz-Zagoya JC, Juárez-Oropeza MA: Protective effect of Arthrospira maxima on fatty acid composition in fatty liver. Arch Med Res 2006, 37:479-483.

49. Bradford MM: $\mathbf{A}$ rapid and sensitive method for the quantitation of microgram quantities of protein utilizing the principle of protein-dye binding. Anal Biochem 1976, 72:248-254.
Publish with BioMed Central and every scientist can read your work free of charge

"BioMed Central will be the most significant development for disseminating the results of biomedical research in our lifetime. "

Sir Paul Nurse, Cancer Research UK

Your research papers will be:

- available free of charge to the entire biomedical community

- peer reviewed and published immediately upon acceptance

- cited in PubMed and archived on PubMed Central

- yours - you keep the copyright
BioMedcentral 